\title{
ANALISIS KEKUATAN PEGAS PRESSURE REDUCER SEBAGAI PENURUNAN TEKANAN PADA MESIN DUEL FUEL
}

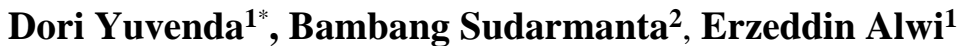 \\ ${ }^{1}$ Jurusan Teknik Otomotif, Fakultas Teknik, Universitas Negeri Padang \\ ${ }^{2}$ Jurusan Teknik Mesin, Fakultas Teknologi Industri, Institut Teknologi Sepuluh Nopember \\ *e-mail: doriyuvenda@ft.unp.ac.id
}

\begin{abstract}
Abstrak-Pressure reducer merupakan komponen utama pada conversion kit pada mesin bahan bakar ganda (duel fuel engine) yang berfungsi sebagai penurun tekanan pada bahan bakar compressed Natural gas dari tangki sebesar \pm 250 bar menjadi tekanan kerja pada injektor gas sebesar \pm 2 bar, sehingga menyebabkan kekurangan pasokan jumlah bahan bakar dari pressure reducer yang berpengaruh tethadap penurunan performa mesin, baik pada saat perubahan putaran mesin secara tiba-tiba maupun perubahan beban mesin. Mengatasi permasalah tersebut maka diperlukan upaya untuk meningkatkan performa pressure reducer agar lebih adaptif terhadap perubahan kondisi mesin. Salah satu upaya yang dilakukan untuk peningkatan performa tersebut adalah menambah kekuatan konstanta pegas pada area chamber stage dua pressure reducer. Penelitian ini menggunakan mesin Diamond tipe DI 800 dengan sistem dual fuel model indirect injection. Metode yang dilakukan adalah menvariasikan kekuatan konstanta pegas $(25,55 \mathrm{~N} / \mathrm{m}, 26,55 \mathrm{~N} / \mathrm{m}$, dan $27,55 \mathrm{~N} / \mathrm{m})$. Hasil terbaik didapatkan pada konstanta pegas $27,55 \mathrm{~N} / \mathrm{m}$ terjadi peningkatan jumlah laju aliran gas (mass flow rate) pada saluran keluar (outlet gas pressure reducer) sebesar $\mathbf{7 , 4 2 \%}$. Hal ini menunjukkan terjadi peningkatan performa pressure reducer pada saat penambahan kontanta pegas pada stage dua.
\end{abstract}

Kata Kunci: Pressure Reducer, konstanta, Laju aliran

\begin{abstract}
Pressure reducer is the main component of conversion kit on dual fuel engine with function as reduction pressure on compressed Natural gas fuel from tank of 250 bar to the working pressure on gas injector of 2 bar, thus causing less of supply amount of fuel from the pressure reducer that affects reduction the engine performance, when changes the engine acceleration or engine load. The solution these problems it are necessary to improve the performance of pressure reducer to be more adaptive to changes in engine conditions. One effort to improve the performance is to increase strength the stiffness of spring in the chamber stage two pressure reducer area. This research uses Diamond type Di 800 dual fuel engine model indirect injection system. The method used is variation the strength of the stiffness of spring $(25,55 \mathrm{~N} / \mathrm{m}$, $26,55 \mathrm{~N} / \mathrm{m}$, and $27,55 \mathrm{~N} / \mathrm{m}$ ). The best result obtained at the stiffness of spring of $27,55 \mathrm{~N} m$ there is an increase in the amount of mass flowrate at the outlet gas pressure reducer of $7,42 \%$. This indicates an increase in pressure reducer performance during the addition of stiffness of spring on stage two.
\end{abstract}

Keywords: Pressure Reducer, stiffness, mass flowrate

Copyright (C) 2017 INVOTEK. All rights reserved

\section{PENDAHULUAN}

Dewasa ini penggunaan bahan bakar alternatif pada mesin pembakaran dalam sangat ditekankan, dikarenakan bahan bakar alternatif mampu mereduksi polusi yang dihasilkan oleh gas buang kendaraan. Salah satu bahan bakar alternatif yang digunakan saat ini adalah bahan bakar gas compressed natural gas (CNG). Disamping ramah terhadap lingkungan bahan bakar ini memiliki cadangan yang sangat banyak di dunia terutama di negara Indonesia [1].

Penggunaan bahan bakar gas CNG belum teroptimalkan semaksimal mungkin pada mesin pemakaran dalam karena terjadinya penurunan performa mesin terutama pada saat kondisi akselerasi dan penambahan beban pada mesin genset. Penyebabnya adalah kurangnya suplai bahan bakar gas CNG pada kondisi tersebut sehingga daya yang di hasilkan lebih rendah[2].

Salah satu penyebab terjadinya kekurangan pasokan bahan bakar adalah kurang adaptifnya sistem penyalur (convertion kit) bahan bakar dari tangki CNG ke ruang bakar mesin sehingga tidak mampu menyuplai gas CNG secara optimal. Komponen utama yang berperan aktif pada 
convertion kit adalah pressure reducer. Pressure reducer berfungsi untuk mengatur tekanan gas CNG dari tangki penyimpanan sebesar 250 bar ke injektor menjadi tekanan kerja sebesar 2 bar. Penurunan tekanan yang signifikan berdampak besar terhadap massa laju aliran fluida (mass flow rate) sehingga mengakibabkan pasokan gas CNG menjadi lebih sedikit.

Untuk mengatasi permasalahan tersebut maka diperlukan pressure reducer yang adaptif terhadap kondisi mesin sehingga lebih responsif dan dapat menambah pasokan bahan bakar gas ke mesin secara tiba-tiba yaitu dengan cara meningkatkan kekuatan dari konstanta pegas ada pada stage dua di area downstream. Stage dua adalah bagian dari daerah pressure reducer yang berfungsi untuk mengatur tekanan kerja keluar gas CNG menuju ke injektor yang terdiri dari diafragma dan pegas penurun tekanan. Cara kerja dari pressure reducer adalah memanfaatkan keseimbangan gaya dengan melalui tiga tahap yaitu loading elemant, sensing element dan control element [3]. Peluang terbesar yang bisa dilakukan untuk pengembangan adalah pada loading element dikarenakan pada tahap ini terdapat pegas sebagai komponen aktuator yang berfungsi sebagai pengontrol bukaan dari needle valve. Lamanya bukaan dari needle valve pada dudukan seat valve akan mempengaruhi tekanan dan aliran yang masuk ke area downstream yang berhubungan langsung dengan outlet gas. Pada saat konstanta $(k)$ pegas ditambah maka gaya beban dari pegas juga meningkat sehingga akan memperlama bukaan sehingga memperbanyak jumlah aliran di oulet gas. Di samping itu juga, mempercepat refleksi pergerakan bukaan dari katup needle valve ketika aliran di oulet gas diinjeksikan secara tiba-tiba oleh injektor rail gas.

\subsection{Pressure Reducer}

\section{STUDI PUSTAKA}

Pressure reducer adalah sebuah komponen utama pada sistem convertion kit yang digunakan untuk mengendalikan dan menjaga tekanan gas keluar agar tetap konstan di bawah perubahan laju aliran dan tekanan masuk. Pressure reducer dirancang dapat beroperasi untuk mendistribusikan gas pada tabung CNG bertekanan tinggi sebesar 250 bar menjadi tekanan kerja sebesar 2 bar sehingga harus memiliki tingkat keamanan yang tinggi dan memenuhi standart internasional yang dikeluarkan oleh badan yang berwewenang.
2.2 Jenis Pressure Reducer

2.2.1 Single Stage

Pada single stage untuk mendapatkan tekanan keluar (delivery pressure) yang sesuai dengan kebutuhan melalui proses satu stage. Penurunan tekanan pada satu stage ini akan memberikan perubahan pada tekanan keluar, dimana dalam banyak kasus ditemukan ketika terjadi penurunan pada tekanan masuk (inlet pressure) maka tekanan keluar akan juga meningkat akibatnya tekanan keluar tidak bisa konstan. Pada single stage hanya memiliki satu elemen control sehingga untuk mempertahankan tekanan keluar tetap stabil sangat sulit. Oleh karena itu, aplikasi penggunaan single stage untuk penurunan takanan lebih cocok untuk fluida gas liquid.

\subsubsection{Dual Stage}

Pada dual stage untuk mendapatkan tekanan keluar yang sesuai degan kebutuhan melalui proses dua stage. Masing-masing stage memiliki komponen pegas (loading element), diafragma (measuaring element) dan needle valve (control element). Pada tahap pertama penurunan tekanan gas CNG sekitar tiga kali dari tekanan kerja maksimum (tekanan inlet) sedangkan untuk tekanan gas keluar pada outlet gas penurunan tekanannya satu kali dari tekanan pada stage satu. Keuntungan dari dual stage adalah kemampuan untuk memberikan tekanan konstan pada tekanan keluar walaupun terjadi penurunan tekanan pada tekanan masuk dan peningkatan pada stage satu.

Pada stage satu kencendrungan terjadi peningkatan tekanan akibat penurunan tekanan gas masuk dari tabung CNG. Kemudian peningkatan tekanan pada stage satu akan diimbangi oleh tekanan pada stage dua oleh control valve sehingga tekanan gas keluar bisa dipertahankan. Jenis dual stage ini lebih cocok digunakan pada fluida gas CNG yang terkompresi 2.3 Komponen Pressure Reducer

Adapun komponen utama dari pressure reducer adalah sebagai berikut:

\subsubsection{Pegas}

Pegas juga disebut dengan loading element yang berfungsi sebagai pengontrol bukaan dari neelde valve. Ada beberapa faktor penting yang harus dipertimbangkan dalam sudut perancangan pegas yaitu jenis material, diameter kawat, diameter pegas, panjang pegas dan jumlah coil sedangkan dari sudut operasional ada faktor yang sangat signifikan yaitu konstanta (spring rate). Spring rate $(k)$ didefinisikan sebagai nilai slope dari kurva gaya defleksi. Untuk kurva gaya 
defleksi yang linier maka konstanta (k) untuk pegas helix tekan adalah

$k=\frac{F}{\Delta l}$

dimana

$$
\begin{aligned}
& k=\text { Kontanta pegas }(\mathrm{N} / \mathrm{m}) \\
& \mathrm{F}=\text { Gaya yang diperlukan }(\mathrm{N}) \\
& \Delta l=\text { Perubahan panjang }(\mathrm{m})
\end{aligned}
$$

\subsection{Performa Pressure Reducer}

Secara teori performa dari sebuah pressure reducer yang bagus adalah tekanan gas keluar tetap konstan pada saat terjadi perubahan laju aliran dan tekanan masuk. Secara teori dapat kita ketahui pada gambar 2.1 berikut:

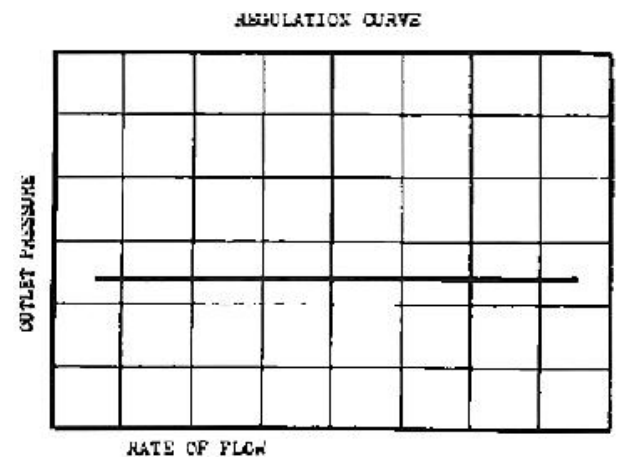

Gambar 1. Grafik performa Pressure reducer secara teori [4]

Pada gambar 1 diatas menjelaskan bahwa performa sebuah pressure reducer yang baik adalah tekanan keluarnya tetap konstan ketika terjadi perubahan laju aliran gas keluar (mass flow rate) dan tekanan masuk, dalam artian tidak ada pressure droop dari awal aliran gas keluar sampai akhir dari gas dimamfaatkan. Akan tetapi dalam kenyataannya untuk mempertahankan performa dari pressure reducer sangat sulit, ketika tekanan dipertahankan konstan namun laju aliran akan berkurang.

Dengan demikian kita bisa menyatakan bahwa persamaan dari tekanan adalah

$P=\frac{F}{A}$

dimana

$$
\begin{aligned}
& \mathrm{P}=\text { Tekanan }\left(\mathrm{N} / \mathrm{m}^{2}\right) \\
& \mathrm{F}=\operatorname{Gaya}(\mathrm{N}) \\
& \mathrm{A}=\operatorname{Area}\left(\mathrm{m}^{2}\right)
\end{aligned}
$$

Tekanan dalam sebuah fluida dalam keadaan diam didefinisikan sebagai gaya normal per satuan luas yang diberikan pada sebuah permukaan bidang (nyata atau semu) yang terendam dalam fluida dan terbentuk dari tumbukan permukaan tersebut dengan molekul-molekul fluida. Untuk mendapatan nilai gaya (N) maka kita bisa menggunakan persamaan 2.1.

Laju aliran gas (mass flow rate) pada gas outlet pressure reduser dapa dihitung dengan menggunakan persamaan sebagai berikut:

$\dot{m}_{3}=\rho . V \cdot A$

dimana

$$
\begin{aligned}
& \dot{m}_{3}=\text { mass flow rate }(\mathrm{kg} / \mathrm{s}) \\
& \rho=\text { Densitas fluida }\left(\mathrm{kg} / \mathrm{m}^{3}\right) \\
& Q=\text { Volume laju aliran }\left(\mathrm{m}^{3} / \mathrm{s}\right) \\
& V=\text { Kecepatan fluida }(\mathrm{m} / \mathrm{s}) \\
& A=\text { Luas area }\left(\mathrm{m}^{2}\right)
\end{aligned}
$$

\subsubsection{Diafragma}

Diafragma yang disebut juga dengan sensing/measuaring element berfungsi sebagai pembatas bukaan dari needle valve dengan cara melawan/mendorong gaya beban pegas akibat dari tekanan yang terbangkitkan di area downstream. Diafragma biasanya dibuat dari bahan elastomer ataupun metal. Kemudian dari proses sensing element meneruskan perubahan gaya yang diterima dari loading mechanism ke control element.

\subsubsection{Needle Valve}

Needle valve juga dengan control element berfungsi sebagai aktuator untuk pembuka atau penutup saluran di seat valve agar aliran bisa masuk ke area downstream. Ketika adjust pressure screw diputar searah jarum jam maka pegas terkompresi sehingga menghasilkan gaya kemudian pegas memindahkan gaya ke diafragama. Diafragma yang menerima gaya beban dari pegas akan memberikan dorongan ke needle valve, menyebabkan needle valve menjauh dari seat valve sehingga lubang orifice menjadi lebih besar akibatnya jumlah aliran gas dan tekanan dapat ditingkatkan dan begitu sebaliknya.

\subsection{Sistem Duel Fuel}

Sistem dual fuel merupakan engine yang menggunakan bahan bakar (2arflda dengan sistem penyuplai berbeda namun penginjeksiannya secara bersamaan. Sistem dual fuel telah banyak beredar dipasaran yang diaplikasikan pada engine diesel. Umumnya yang banyak dijumpai adalah menggunakan bahan bakar Compressed Natural Gas (CNG) dan solar.

Teknologi sistem pemasukan bahan bakar CNG ke ruang bakar mesin saat ini adalah

2.5.1.1 Model mixer/blender yang berbentuk yang berbentuk venturi sehingga gas $\mathrm{CNG}$ 
masuk ketika terjadi langkah hisap pada saat katup masuk membuka.

2.5.1.2 Model indirect injection dimana injektor gas CNG bertekanan rendah yang diletakkan di mulut saluran masuk (port) sehingga gas CNG diinjeksikan disesuaikan dengan pembukaan katup masuk yang dikontrol secara elektronik.

2.5.1.3 Model direct injection dimana injektor gas CNG yang bertekanan tinggi langsung menginjeksikan gas CNG ke ruang bakar pada akhir langkah kompresi.

\section{METODE}

Metode penelitian yang digunakan pada penelitian ini adalah metode eksperimental. Pengujian dilakukan pada mesin diesel dengan menggunakan bahan bakar ganda. (duel fuel). Bahan bakar diesel dikombinasikan dengan bahan bakar gas CNG dengan menggunakan sistem convertion kit yang dikontrol secara elektronik.
Adapun komponen utama dari sistem convertion kit adalah Tangki CNG, Selang tekanan tinggi, Pressure reducer, injektor gas dan Electronic control unit (ECU). Untuk mendapatkan performa pressure reducer yang optimal maka dilakukan variasi kekuatan/konstanta pegas di chamber dua pressure reducer sebagai variabel bebas. Konstanta pegas standart sebagai variabel kontrol, sedangkan jumlah aliran gas rata-rata (mass flow rate) dari pressure reducer sebagai variabel terikat. Adapun rancangan penelitian pressure reducer dengan memasang pressure gauge pada saluran masuk (inlet gas), chamber stage satu, chamber stage dua, saluran keluar (outlet gas) pressure reducer, dan untuk mengetahui (laju aliran gas) mass flow rate maka dipasang flow rate meter, untuk lebih jelasnya terlihat pada gambar di bawah ini:

Gambar 2. Gambar prosedur penelitian pada pressure reducer dengan pemasangan alat ukur pressure gauge

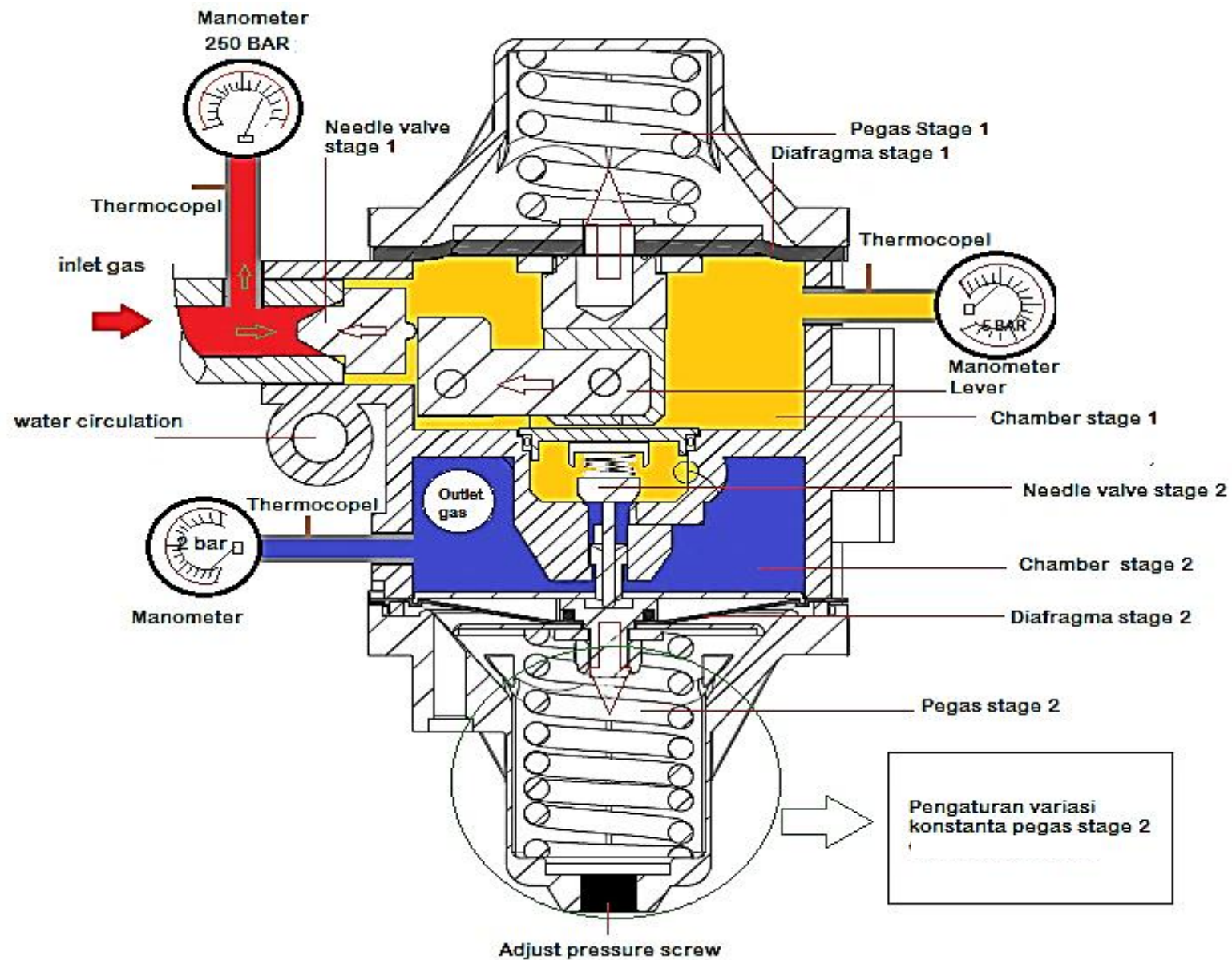


Tabel 1. Spesifikasi pressure reducer sebagai berikut:

\begin{tabular}{|l|l|}
\hline \multicolumn{1}{|c|}{ Item } & \multicolumn{1}{c|}{ Spesifikasi } \\
\hline Model & $\begin{array}{l}\text { Type of product CNG } \\
\text { sequential reducer }\end{array}$ \\
\hline Material & $\begin{array}{l}\text { Die-cast Aluminium } \\
\text { body, CNC machined }\end{array}$ \\
\hline Weight & $1,50 \mathrm{~kg}$ \\
\hline Max. inlet pressure & $26,00 \mathrm{MPa}$ \\
\hline $1^{\text {st }}$ stage pressure & $0,50 \mathrm{MPa}$ \\
\hline Solenoid voltage & $12 \mathrm{~V}$ \\
\hline $\begin{array}{l}\text { Solenoid power } \\
\text { dissipation }\end{array}$ & $17 \mathrm{~W}$ \\
\hline Inlet connection $\varnothing$ & $6.0 \mathrm{~mm} \mathrm{M12x1}$ \\
\hline $\begin{array}{l}\text { Outlet connection } \\
\text { fitting } \varnothing\end{array}$ & $13,5 \mathrm{~mm}$ \\
\hline Flow rate & $35 \mathrm{~kg} / \mathrm{h} \mathrm{CH} 4$ \\
\hline
\end{tabular}

menggunakan metode true experimental method. Data yang diperoleh digambarkan dalam bentuk grafik dan dideskripsikan dalam bentuk kalimat yang mudah dibaca, dipahami dan dipresentasikan sebagai jawaban atas permasalahan yang diteliti. Skema rancangan penelitian yang digunakan dalam penelitian ini terlihat pada gambar di bawah ini:

Teknik analisis data yang digunakan dalam penelitian ini adalah analisis data secara statistik

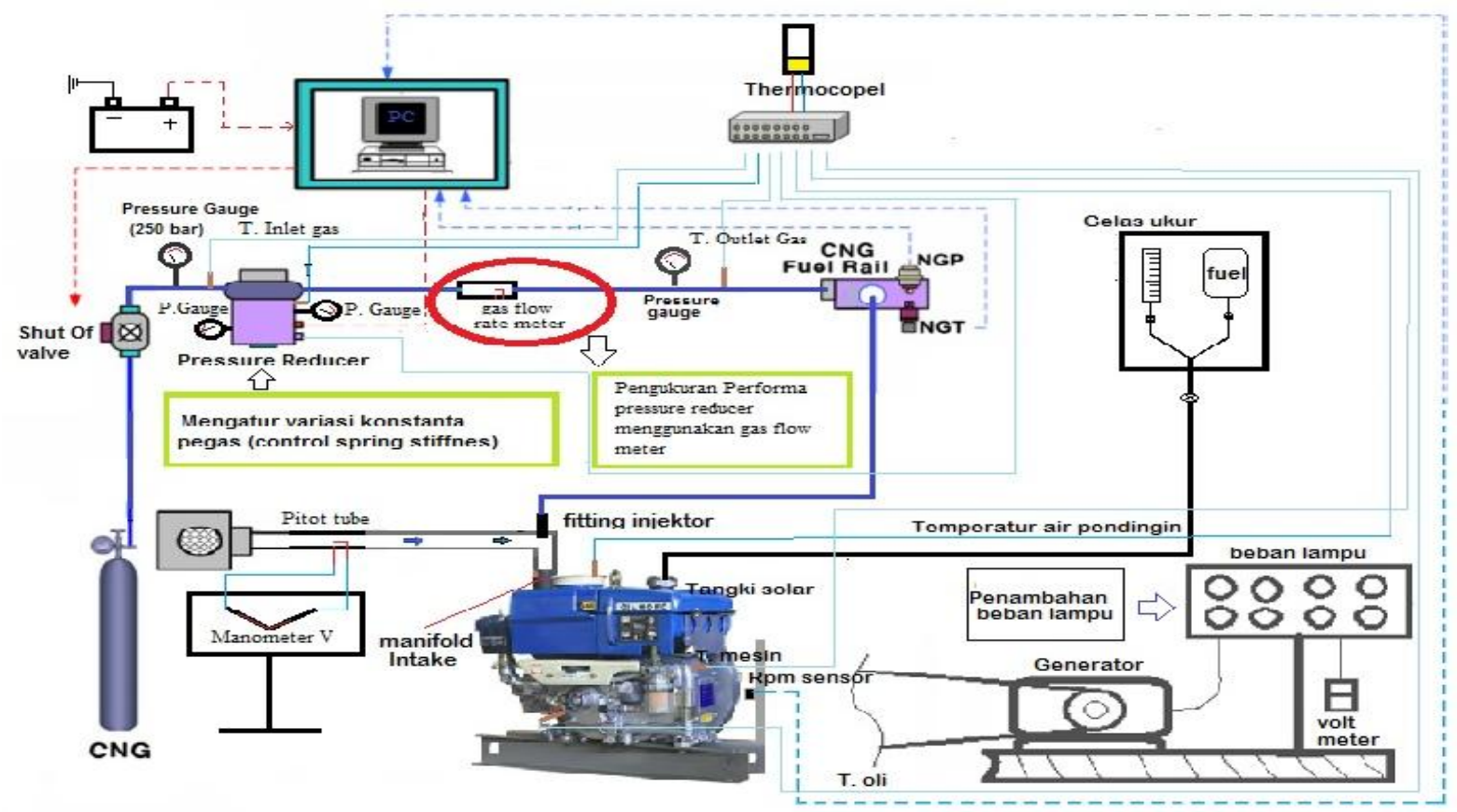

Gambar 3. Skema penelitian pressure reducer dengan sistem convertion kit pada mesin duel fuel

IV.

\section{HASIL DAN PEMBAHASAN}

Pressure reducer salah satu komponen convertion kit pada mesin duel fuel yang berfungsi untuk menurunkan tekanan pada tangki CNG menjadi tekanan kerja pada mesin. Proses penurunan tekanan akan mempengaruhi jumlah flow rate gas keluar pada pressure reducer. Tekanan dan jumlah flow rate yang dihasilkan pada oulet pressure reducer dipengaruhi oleh konstanta pegas.

\subsection{Pengaruh konstanta pegas terhadap tekanan}

Tekanan gas keluar pada pressure reducer mempengaruhi kuantitas flow rate gas yang keluar melalui gas outlet. Untuk itu tekanan gas keluar harus dijaga konstan. Tekanan gas keluar di outlet gas dapat dipertahankan apabila tekanan pada area stage dua bisa terjamin. Untuk menjamin tekanan 
pada area stage dua dipengaruhi oleh kekuatan konstanta pegas yang ada pada area chamber stage dua. Berdasarkan penelitian yang telah dilakukan dengan memvariasikan tekanan konstanta pegas maka diperoleh hasil tekanan sebagai berikut:

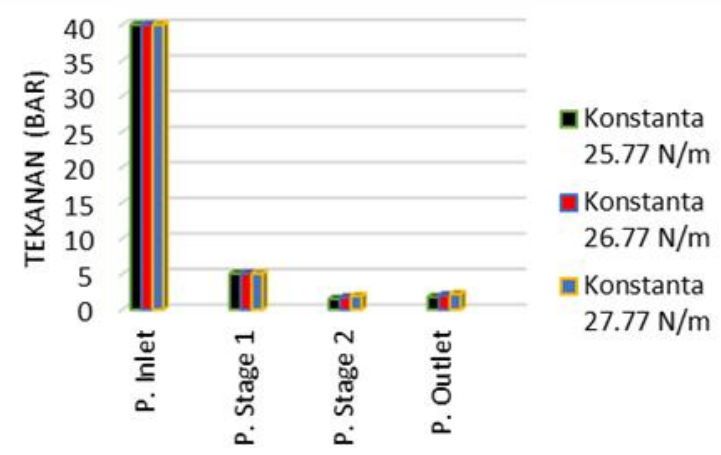

Gambar 4. Pengaruh konstanta pegas terhadap tekanan pada pressure reducer

Pada gambar 4 secara umum menunjukkan bahwa pada tekanan gas di area stage satu terjadi penurunan yang signifikan pada sebesar 5 bar dari tekanan gas di area inlet gas namun tidak terjadi perbedaan tekanan di setiap percobaan karena kekuatan konstanta pegas pada stage satu sama, sedangkan tekanan gas pada stage dua dan oulet gas terjadi perbedaan pada setiap variasi kekuatan konstanta pegas, dimana terjadi kenaikan tekanan gas secara linear ketika konstanta pegas di area stage dua ditingkatkan. Peningkatan tekanan gas terbesar di area stage dua dan oulet gas terjadi pada konstanta pegas $27,77 \mathrm{~N} / \mathrm{m}$ dengan tekanan gas sebesar 1,9 bar dan 2,2 bar. Hal ini mebuktikan bahwa ketika kekuatan konstanta pegas pada stage dua ditingkatkan/ditambah maka akan mempengaruhi waktu pembukaan dari needle valve menjadi lebih lama sehingga terjadi peningkatan tekanan pada area stage dua. Peningkatan tekanan gas pada area stage dua juga akan diikuti oleh peningkatan tekanan gas keluar di area outlet gas. Tekanan gas keluar tetap konstan apabila penurunan tekanan di area stage dua tidak terlalu besar. Dengan demikian untuk menjaga performa pressure reducer agar lebih optimal maka dibutuhkan tekanan yang konstan pada area stage dua dengan cara meningkatkan kekuatan pegas pada area tersebut sehingga akan memperkecil pressure drop pada area oulet gas.

\subsection{Pengaruh konstanta pegas terhadap mass flow rate gas}

Laju aliran gas (mass flow rate gas) merupakan parameter utama untuk menentukan performa dari pressure reducer. Ketika laju aliran bisa ditingkatkan maka pasokan bahan bakar gas bisa diperbanyak ke ruang bakar melalui gas injector.

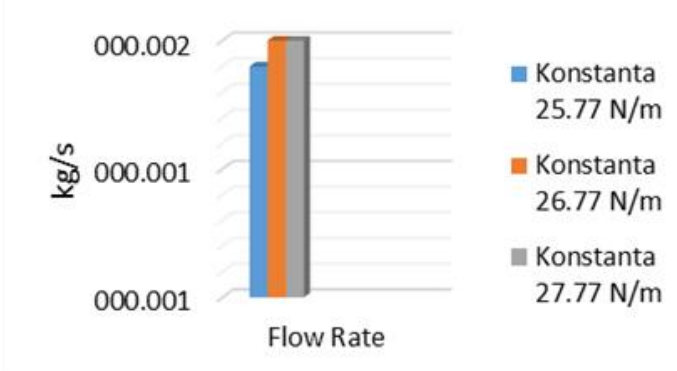

Gambar 5. Pengaruh konstanta pegas terhadap kuantitas mass flow rate gas pada pressure reducer

Gambar 5 secara umum menunjukkan bahwa tejadi peningkatan laju aliran gas (mass flow rate) pada oulet pressure oulet gas ketika kekuatan konstanta pegas ditingkatkan. Pada konstanta pegas $27,77 \mathrm{~N} / \mathrm{m}$ menghasilkan mass flow rate tertinggi sebesar $0,35336 \mathrm{~kg} / \mathrm{h}$ dengan peningkatan persentase rata-rata sebesar $7,42 \%$ dari pegas standart $(25,77$ $\mathrm{N} / \mathrm{m}$ ). Hal ini membuktikan bahwa ketika konstanta pegas ditingkatkan maka akan memperlama waktu pembukaan dari needle valve sehingga mass flow rate lebih banyak masuk ke chamber stage dua sehingga akan berdampak pada laju aliran pada outlet gas. Kemudian dengan menambah kekuatan konstanta pegas akan mempercepat sensivitas refleksi pegas untuk pembukaan needle valve ketika terjadi pengosongan mass flow rate di chamber stage dua pada saat bahan bakar gas di injeksikan secara tiba-tiba oleh gas injector, sehingga jumlah mass flow rate pada chamber stage dua bisa tetap terjamin. Dengan demikian pressure reducer lebih adaptif terhadap kondisi akselerasi penambahan kecepatan dan penambahan beban pada genset. Penurunan mass flow rate juga dipengaruhi oleh seiring dengan pertambahan waktu seperti terlihat pada grafik 6.

Pada gambar 6 terlihat bahwa penurunan mass flow rate dipengaruhi oleh pertambahan waktu untuk mencapai titik puncak konstan. Pada konstanta pegas 27,77 N/m terlihat penurunan mass flow rate tidak signifikan dan mencapai titik kosntan dalam waktu yang cepat dari variasi pegas lain. Hal ini membuktikan bahwa peningkatan konstanta menyebabkan sensivitas pegas lebih tinggi sehingga apabila terjadi pengosongan pada chamber dua secara tiba-tiba pegas merefleksi lebih cepat sehingga mass flow rate bisa dipertahankan. 


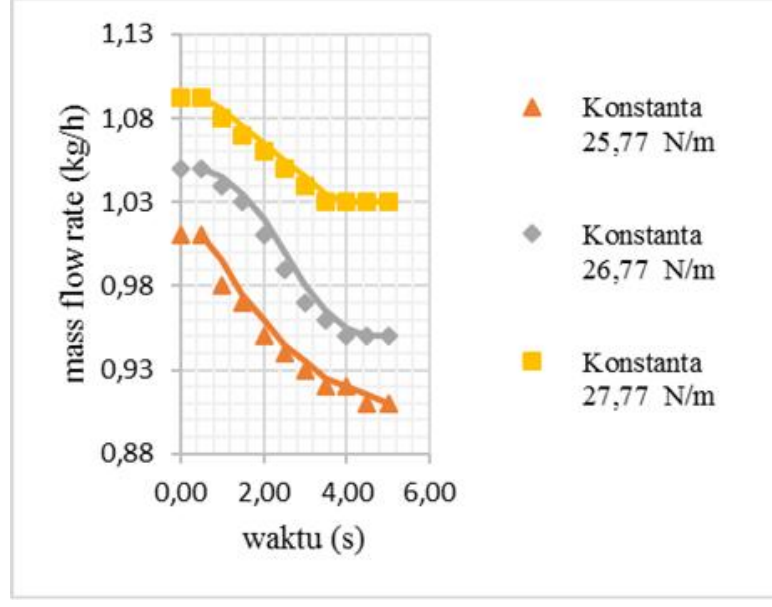

Gambar 6. Mass flow rate fungsi waktu

Pada dasarnya peningkatan dari mass flow rate disebabkan oleh peningkatan dari debit aliran (volume flow rate) seperti yang terlihat pada gambar 7 .

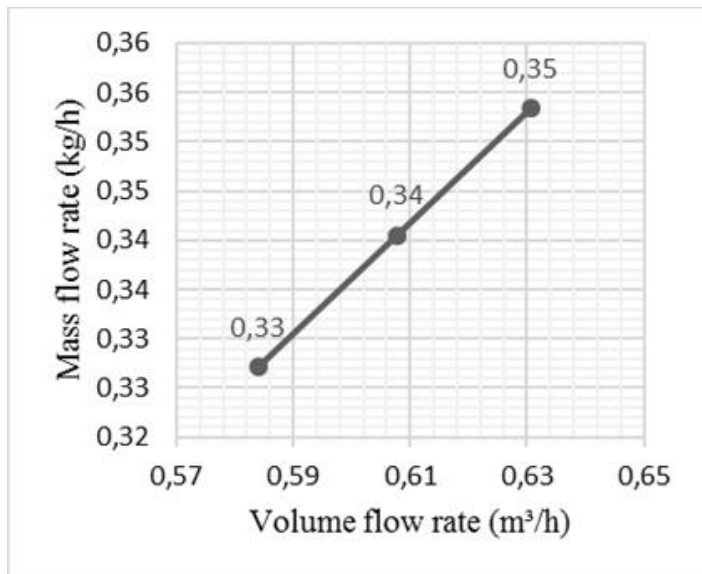

Gambar 7. Mass flow rate fungsi volume flow rate

Pada gambar 7 menunjukkan bahwa terjadi peningkatan volume flow rate ketika konstanta pegas ditingkatkan. Peningkatan tertinggi terjadi pada konstanta pegas $27,77 \mathrm{~N} / \mathrm{m}$ sebesar $0,63 \mathrm{~m}^{3} / \mathrm{h}$. Hal ini membuktikan bahwa ketika konstanta pegas ditingkatkan waktu pembukaan dari needle valve pada stage dua lebih lama sehingga menyebabkan aliran lebih banyak masuk ke chamber stage dua. Ketika laju aliran (mass flow rate) diperbanyak di chamber dua maka akan terjadi kenaikan dari volume flow rate atau debit aliran. Sedangkan peningkatan volume flow rate secara linear akan diikuti oleh peningkatan dari mass flow rate.
Dalam kata lain bahwa debit aliran fungsi dari laju aliran massa.

\section{KESIMPULAN}

Berdasarkan hasil penelitian maka dapat disimpulkan bahwa penambahan kekuatan konstanta pegas di area stage dua pressure reducer sebesar $27,77 \mathrm{~N} / \mathrm{m}$ dapat meningkatkan performa pressure reducer yang lebih adaptif sehingga dapat memperbanyak jumlah mass flow rate yang keluar melalui outlet gas dan juga dapat memepertahankan tekanan gas keluar secara konstan dalam waktu yang lebih lama.

\section{DAFTAR PUSTAKA}

[1] Tim BPPT, Indonesia Energy Outlook. Center for Technology of Energy Resources and Chemical Industry (2016)

[2] Angkasa, A. Optimasi Kinerja Mesin Sinjai Bi-Fuel Bensin dan Compressed Natural Gas $(C N G)$ dengan Variasi Tekanan Masuk dan Derajat Pengapian, Tesis Magister, Institut Teknologi Sepuluh Nopember Surabaya (2014)

[3] Matheson. Guide to regulator. USA: Matheson Tri-Gas, Inc. (2014)

[4] Mally, E.,C. Gas Appliances Engineers Handbook. National Gaes Award (1963)

\section{Biodata Penulis}

Dori Yuvenda, lahir di Bukittinggi, 1 Nopember 1988. Sarjana Pendidikan di Jurusan Teknik Otomotif FT UNP 2013. Tahun 2013 memperoleh gelar Magister Teknik di jurusan Teknik Mesin Program Pascasarjana ITS dengan bidang konsentrasi Rekayasa Konversi Energi. Staf pengajar di jurusan Teknik Otomotif FT UNP sejak tahun 2015- sekarang.

Bambang Sudarmanta, Asal Surabaya. Telah menyelesaikan program Doktor di Pascasarjana ITS dengan jurusan Teknik Mesin dengan konsentrasi Konversi Energi. Saat ini menjadi staf pengajar di jurusan Teknik Mesin Fakultas Teknologi Industri ITS.

Erzeddin Alwi, Asal Padang. Telah menyelesaikan program Magister Pendidikan di Pascasarjana UNP. Saat ini menjadi staf pengajar di jurusan Teknik Otomotif FT UNP. 
